\title{
CALCIUM BLOCKERS ON THE HEALING OF DENTAL EXTRACTION WOUNDS: HISTOLOGICAL INVESTIGATION IN RATS
}

\author{
BASTOS-RAMOS, W. P. ${ }^{1}$; OTT, A.P.O. ${ }^{1}$; SAMPAIO, T.A. ${ }^{1}$; CABRAL, V.N. ${ }^{1}$; \\ GOMES, M.F. ${ }^{1}$; MANCINI, M.N.G. ${ }^{1}$; GOULART, M.G. ${ }^{2}$ \\ ${ }^{1}$ Departamento de Biociências e Diagnóstico Bucal, Faculdade de Odontologia de São José \\ dos Campos, UNESP; \\ ${ }^{2}$ Departamento de Ciências Fisiológicas, Faculdade de Odontologia, UNICAMP.
}

The calcium blocking drugs are important in clinical practice, used for long term treatment of cardiovascular diseases. Verapamil (Dilacoron $®$ ) and nifedipine (Adalat $($ ) are amongst the most widely used. Their actions on bone tissue are about unknown. In the present research, it was studied in rats the effects of these drugs on the alveolar healing after dental extraction as well as on the growth of other osseous tissues (teeth and femoral bone). Assayed of blood calcium, phosphate and alkaline phosphatase has been carried out. 4 Material and Methods. Forty four male Wistar rats were used (experimental and control groups). The animals were treated with either drug, by oral route during 7 days before and along 7, 14 or 21 days after the dental extraction. The rats were divided in two groups: a) - treated with verapamil 2.4 $\mathrm{mg} / \mathrm{rat} / \mathrm{day}$; b) - treated with nifedipine $1.5 \mathrm{mg} / \mathrm{rat} / \mathrm{day}$. The upper left incisor was extracted and the right one marked for growth measurement. Seven, 14 or 21 days later, the animals were killed, the blood collected for biochemical assays and isolation of the femoral bone. The left inferior mandible was isolated and alveolar pieces prepared to histology, stained by Mallory's method. Results: 1- verapamil caused a higher dental growth while such result was not observed with nifedipine; 2 the drugs did not modify the femoral bone growth; 3 - verapamil did not retard the repairing process, as expected, tending, on the contrary, to stimulate the process in the observations at 14 and 21 days, in parallel with significant rise of blood calcium and alkaline phosphatase. The results with nifedipine were not conclusive.

Key Words: Verapramil, Nifedipine, dental caries, femoral bone, wistar rat. 